\title{
Tendencies of University Student Athletes to Recognize and to Deal with the Difficult Events-For Rugby Team Members
}

\author{
Shogo Komatsu \\ Yokohama City University Medical Center, Yokohama, Japan \\ Email: look.what.happened.7700@gmail.com
}

How to cite this paper: Komatsu, S. (2019) Tendencies of University Student Athletes to Recognize and to Deal with the Difficult Events-For Rugby Team Members. Open Journal of Social Sciences, 7, 301-308. https://doi.org/10.4236/jss.2019.710025

Received: September 11, 2019

Accepted: October 20, 2019

Published: October 23, 2019

Copyright $\odot 2019$ by author(s) and Scientific Research Publishing Inc. This work is licensed under the Creative Commons Attribution International License (CC BY 4.0).

http://creativecommons.org/licenses/by/4.0/

\section{(c) (i) Open Access}

\begin{abstract}
Regarding research targeting on athletes, many quantitative studies such as questionnaire item surveys have been performed, on the other hand, the qualitative research using a free description of athletes has been conducted less than the former. In this study, this Cluster analysis is used to analyze the data of free description of university student athletes, and to clarify the characteristics of tendencies of university student athletes to recognize and to deal with the difficult events. Using Cluster analysis, tendencies for difficult events between regular and non-regular players were studied. As a result, compared to non-regular players, regular players were more aware of the importance of injuries and were more aware of the importance of dealing with injuries with physical therapies and treatment.
\end{abstract}

\section{Keywords}

Cluster Analysis, Athletes, Injury

\section{Introduction}

At present, athletes in Japan have been supported proactively for the psychological aspects. According to Tachiya (2013), psychological supports for top athletes have started from the 2008 Beijing Olympics, and at the 2012 London Olympics, the supports were called the "Team Japan Multi-Support Project" and it has been reported that psychological supports were fully provided as part of the supports [1]. Therefore the enhancement of the support system has increased the opportunities for many athletes to approach the sports not only from the technical and physical aspects but also from the psychological aspects as well (Fukui, Toyoda, Takeuchi, 2015) [2]. 
It has been known that sports activities have positive aspects to improve mental and physical functions and to maintain good health. However, at the same time, it has also been well known that there are times that it is difficult to continue a competition for athletes when they have placed a burden or when they are under pressure of being technically better than them. A study of junior and senior high school students' athletic clubs said that the physical and mental burdens associated with sports activities include four factors: "physical burden", "no progress", "environmental changes" and "human relationships" (Kanou, Endo, Oishil, 2011) [3].

The experience of such difficulties is generally reminiscent of negative images, but there have been many reports indicating how these athletes improve competitive abilities and experience psychological growth after overcoming these difficulties.

Considering how these difficult experiences affect competitors subsequently, it is an important process to give meanings to the point (Frazier, 2009; Park, 2010) [4] [5]. And it is also important how they have responded to difficulties for the competitor's subsequent adaptation (Janoff-Bulman, 2006) [6]. Therefore, in order to understand the psychological changes that occur subsequent to difficult experiences, it is important to consider how to recognize difficult events and how to deal with them. However, it has not been studied for this much except case studies (Kimura, Oishi, 2016) [7].

In addition, regarding research targeting on athletes, many quantitative studies such as questionnaire item surveys have been performed, on the other hand, the qualitative research using a free description of athletes have been conducted less than the former. In recent years, various methods have been proposed for analyzing qualitative data such as free description. Cluster analysis, which is included in those methods, is an analysis method that groups words with similar appearance patterns into the same group, and is used in various fields such as medical symptom classification, industrial product classification, and literature classification. It is one of the greatest features of this analysis method to realize the main theme of the text by assigning an appropriate title.

In this study, this Cluster analysis is used to analyze the data of free description of university student athletes, and to clarify the characteristics of tendencies of university student athletes to recognize and to deal with the difficult events. Clarifying the cognitive and coping tendencies for this difficult event is considered meaningful in providing psychological support according to the psychological characteristics of individual athletes, including mental training.

\section{Analysis Method}

This analysis was performed for 68 members of the rugby team at A University using Google Form during the period from June 2019 to August 2019. Google Forms is a tool that can be used for various purposes such as surveys and voting. It's easy to create from Google Drive and spreadsheets, and answers are auto- 
matically aggregated. The questionnaire contained these questions about the difficult events that they have experienced, and these students answered in the free description: 1) "What kind of difficulties did you experience?", 2) "How did you think when you experienced the difficult event?", 3) "When you experienced the difficult event, how did you try to solve it?", and 4) "How do you think the difficult experience had an impact on your current way of thinking?". The number of valid responses was 60 .

The procedures of this analysis are as follows. Free text data on difficult events obtained from 60 people was created and $\mathrm{KH}$ Coder was used. In preprocess of KH Coder, words are extracted from the text data using a morphological analysis system. The extracted words were grouped by Cluster analysis (Figure 1).

\section{Results and Discussion}

The text data on 4 questions obtained from 60 people were inputted into $\mathrm{KH}$ Coder, and 30 words in descending order of appearance were extracted for each question item (Table 1). Considering the result, regarding the question item (1) "What kind of difficulties did you experience?", the item "Injuries" appears the most, and words such as "Competition" and "Play" follow. In general, for athletes, injuries are one of the most serious events that threaten their carries as athletes, and for rugby players of A University, "Injuries" are considered as a strong impact on all the events they have experienced. Also, it is difficult for the players to go on the game under the pressure. The reasons for the retirement of athletes in Japan are included as; drop in competitiveness, inadequate environment, and injuries/illness (Toyoda \& Nakagome, 1996) [8], a graduation of university/job-hunting and employment, decline in energy, injuries/illness (Oba \& Tokunaga, 1998) [9], etc. And it has been pointed out that top athletes often continue to play the sports even if they are injured and they continuously are suffering from chronic pain to pursue themselves physically and mentally to succeed (Naoi, 2009) [10].

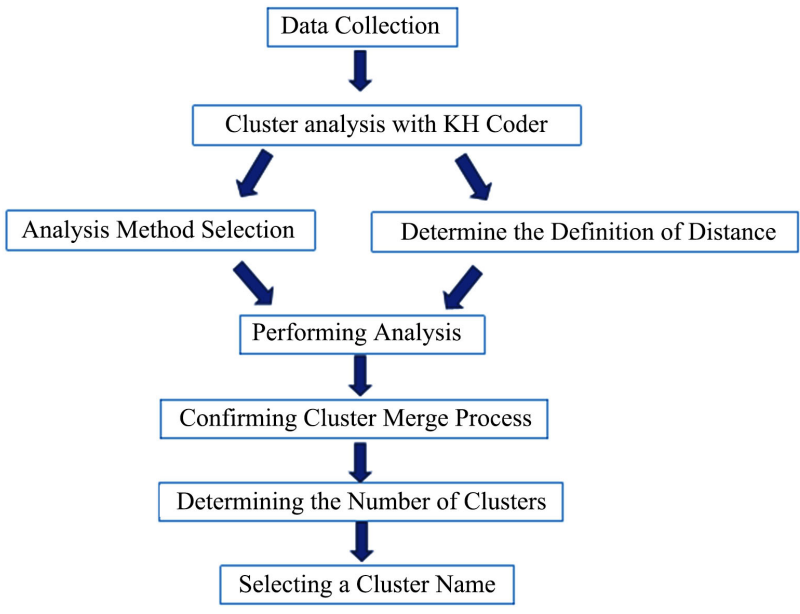

Figure 1. Analysis procedure for this study. 
Table 1. Words extracted from question item (1) and the number of the words Extracted words/Number of Appearances.

\begin{tabular}{|c|c|}
\hline Extracted words & Number of Appearances \\
\hline Injuries & 25 \\
\hline Competition & 8 \\
\hline Play & 6 \\
\hline Myself & 6 \\
\hline Team Mates & 4 \\
\hline Team & 3 \\
\hline Regular Member & 3 \\
\hline Think & 3 \\
\hline Many & 3 \\
\hline Important & 3 \\
\hline Practice & 3 \\
\hline $\mathrm{A}$ & 2 \\
\hline Communication & 2 \\
\hline Level & 2 \\
\hline Technique & 2 \\
\hline Hard-Works & 2 \\
\hline Surgery & 2 \\
\hline Possibility & 2 \\
\hline Improvement & 2 \\
\hline Forward & 2 \\
\hline Continue & 2 \\
\hline Stamina & 2 \\
\hline Jump & 2 \\
\hline Come Back & 2 \\
\hline Power & 2 \\
\hline Beautiful & 1 \\
\hline Kick & 1 \\
\hline Signature/Autograph & 1 \\
\hline Scram & 1 \\
\hline Sports & 1 \\
\hline
\end{tabular}

In Figures 2-5, the results of Cluster analysis were summarized for all data. In this analysis, the minimum number of appearances was set to " 3 ", the distance (similarity) index was set to Jaccard, and the inter-Cluster distance measurement method was set to the group average method. The group average method is a method in which the average of all the distances between samples included in each Cluster is regarded as the similarity between both.

Carefully taking a close look at the words belonging to each Cluster with question items (1) to (4), it enables to give the following titles.

In item (1), Cluster 1 is named as "Injuries", Cluster 2 as "Play", Cluster 3 as "About Myself", and Cluster 4 as "Events during the Competition". Also, looking at the breakdown of regular and non-regular members for this question item (1), Cluster 1 "injuries" has the highest ratio among regular members, on the other hand, other Clusters have few or no ratio among non-regular members. This implies that regular members are more aware of the difficulty of being injured that they have experienced so far (Figure 2).

Secondly, in item (2), Cluster 1 is named as "Grief", Cluster 2 as "Give up", Cluster 3 as "Weakness", Cluster 4 as "Solution-oriented", Cluster 5 as "Practice-oriented", and Cluster 6 as "Anxiety and impatience". Also, regarding this 
question item (2), looking at the breakdown of regular and non-regular members for each Cluster, there are no big differences between the Clusters regarding tendencies to recognize difficult events between regular and non-regular members (Figure 3 ).

In item (3), Cluster 1 is named as "Physical Therapy and treatment", Cluster 2 as "Review and reflection for the play", and Cluster 3 as "Practice". Regarding this question item (3), looking at the breakdown of regular and non-regular members for each Cluster, the ratio of regular members in Cluster 1 "Physical Therapy and treatment" was high. This suggests that regular members are more aware of the importance of treatments for injuries and subsequent physical therapies (Figure 4).

In item (4), Cluster 1 is named as "Impact on myself", Cluster 2 as "Importance of practice", Cluster 3 as "Confidence and trust", Cluster 4 as "Consciousness to injuries", and Cluster 5 as "Importance of friendships and experience". Also, regarding this question item (2), looking at the breakdown of regular and non-regular members for each Cluster, there are no big differences between the Clusters, and there is less difference on tendencies to recognize difficult events between regular and non-regular members (Figure 5).

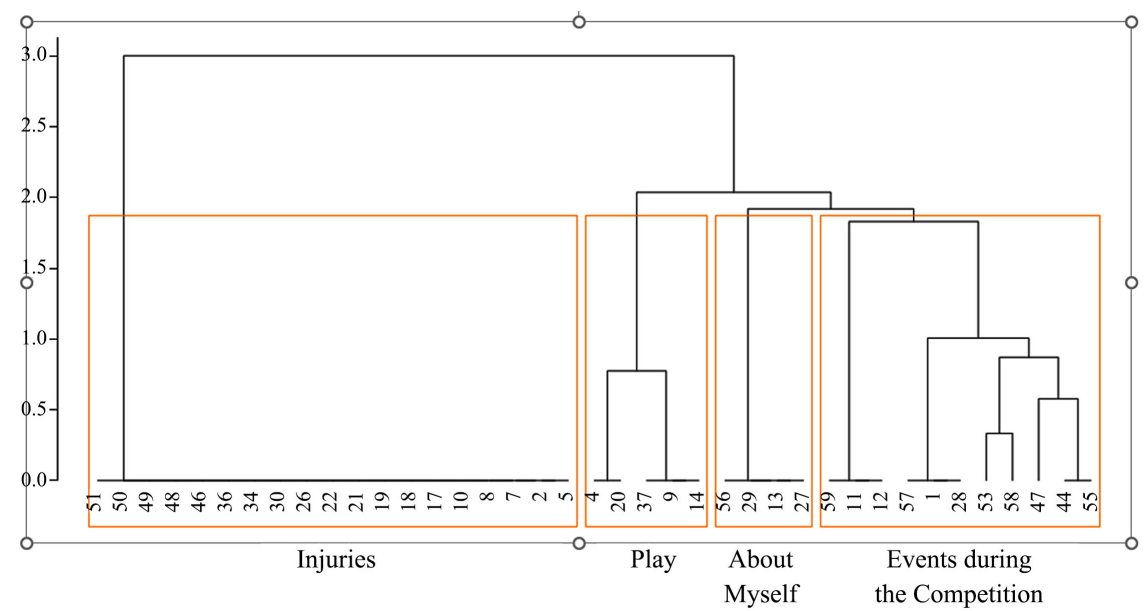

Figure 2. Result of cluster analysis of item (1).

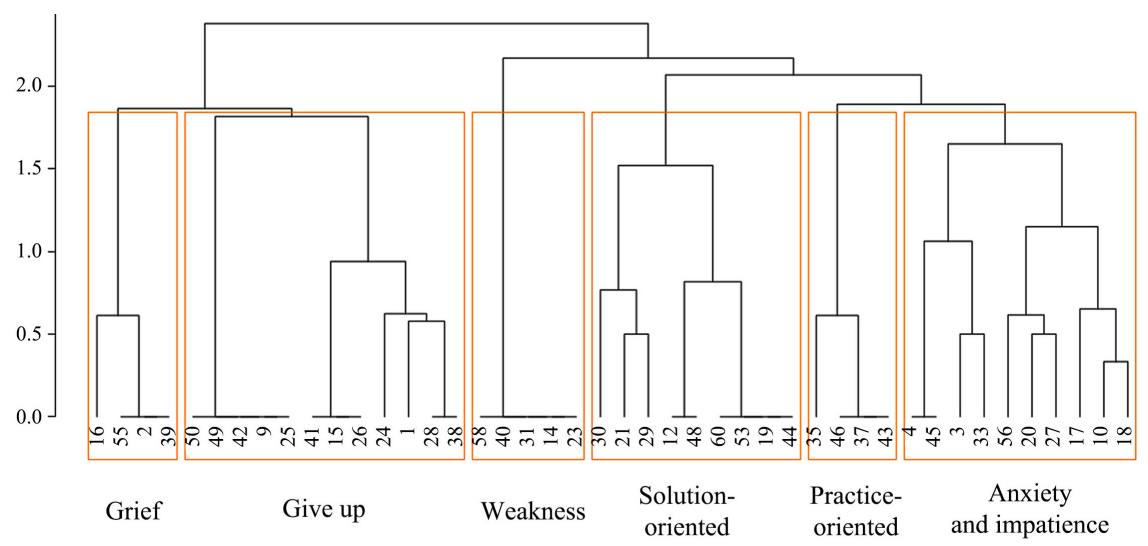

Figure 3. Result of cluster analysis of item (2). 


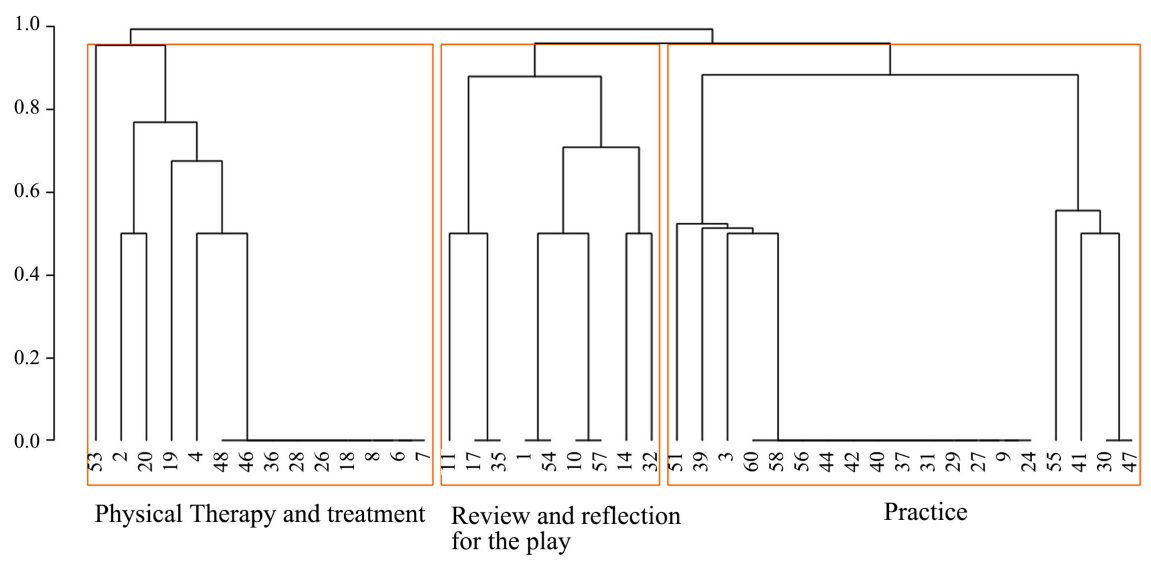

Figure 4. Result of cluster analysis of item (3).

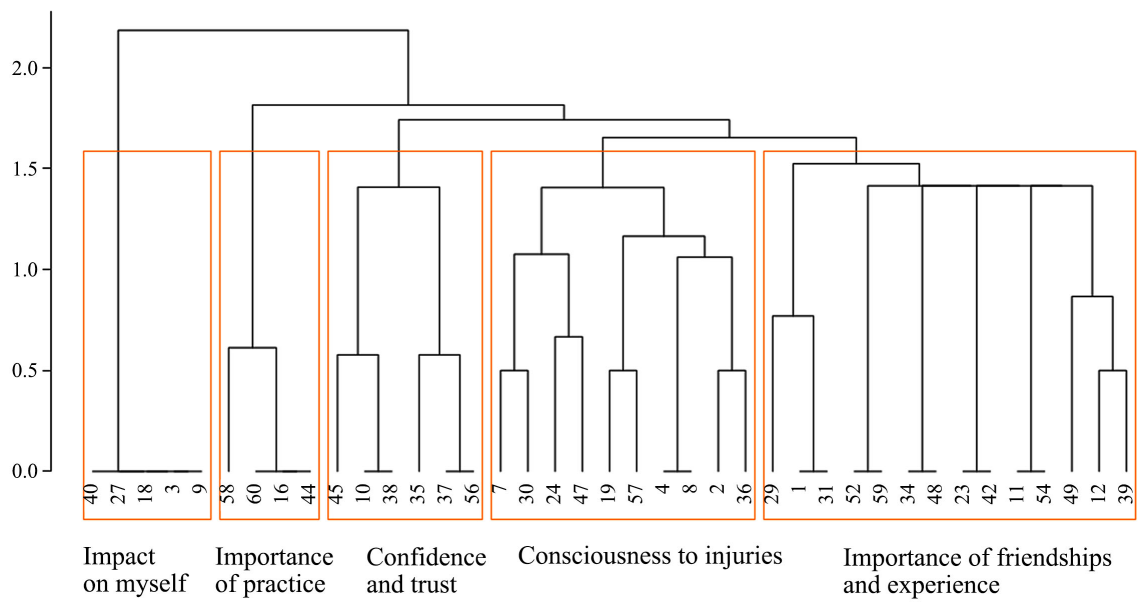

Figure 5. Result of cluster analysis of item (4).

\section{General Discussion}

Using Cluster analysis, tendencies for difficult events between regular and non-regular players were studied. As a result, compared to non-regular players, regular players were more aware of the importance of injuries and were more aware of the importance of dealing with injuries with physical therapies and treatment. For student athletes, it is difficult to adapt to injuries in various ways and can develop into serious psychological problems (Uemukai, 2000) [11]. For athletes, injuries are serious events that temporarily interrupt the continuation of the competition, and can also affect one's carrier as an athlete. Therefore, it seems that regular players are more concerned about losing regularity when they are injured, and they are always strongly aware of the injuries. Toyoda (2007) [12] also reported that injuries were major turning points for student athletes, and they had mentally experienced self-growth through their experiences. Hence, it is also important to have the process of acquiring positive attitudes by individuals through confronting and overcoming the internal challenges to negative experience such as injuries for self-growth. It also implies that the regular player experienced difficult events caused by being injured, and they overcame 
these difficulties.

When it comes to studying difficult events for athletes, people tend to more value on performances or results in competitions. However, this study shows that there are so many words about injuries appeared on the result, and it seems that it is a very impactful experience for athletes. Hence, it is very important to value not only the maintenance of daily competitive ability but also how to overcome the injuries physically and mentally in providing psychological supports for athletes. Especially for those who were selected as regular members, these pressures are considered as psychologically substantial.

However, not everyone can overcome the difficult events of injuries, and these events can lead to burnout, dropout, loss of motivation, and various psychopathological problems. It is necessary to approach not only medical treatments for this matter but also psychologically to related problem events.

As a result of a Cluster analysis using text data of university student athletes, it shows that injuries are serious events for athletes and they were highly aware of their treatment. This result suggests that players with higher abilities, such as regular players, need to have the characteristic of "high crisis awareness" in addition to high level of skill and physical ability.

When performing athletes' mental training, it may be necessary to take approaches considering the factors of injuries. Therefore, in order to carry out mental training more effectively, it is necessary to establish comprehensive assessment methods for injuries taking into account for the injuries, the degree of injuries, and the stage of treatments. Further study for this matter using quantitative data is considered necessary.

In this study, the relationship between Clusters could not be examined. In addition to this, the number of people in some Clusters has become very small, making it impossible to make statistical comparisons.

Therefore, in the future, it is the next challenge to increase the number of participants and examine differences and relationships between Clusters.

\section{Acknowledgements}

I would like to thank Mr. Akira Rinoshika, Mr. Kensei Tuchida, Ms. Chieko Kato and Mr. Koichiro Aoki for their advice and guidance to conclude this thesis.

\section{Conflicts of Interest}

The author declares no conflicts of interest regarding the publication of this paper.

\section{References}

[1] Tachiya, Y. (2013) Activities for Psychological Supports by JISS for the London Olympics. Report and Key Note Lecture 1 of Bulletin of Japan Sports Council EXpertise in Psychological Fields, 53, 7-25.

[2] Fukui, K., Toyoda, N. and Takeuchi, S. (2015) The Effect of Mental Training Expe- 
riences for Student-Athletes: Focused Relaxation Ability and Introspective Reports. Studies in Biwako Seikei Sport College, 12, 61-67.

[3] Kanou, H., Endo, S. and Oishi, K. (2011). Zasetsu among Male Junior and Senior High School Athletes, and the Process by Which It Is Overcome. Studies of Physical Education, 56, 89-103. https://doi.org/10.5432/jjpehss.10018

[4] Frazier, P., Tennen, H., Gavian, M., Park, C., Tomich, P. and Tashiro, T. (2009) Does Self-Reported Posttraumatic Growth Reflect Genuine Positive Change? Psychological Science, 20, 912-919. https://doi.org/10.1111/j.1467-9280.2009.02381.x

[5] Park, C.L. (2010) Making Sense of the Meaning Literature: An Integrative Review of Meaning Making and Its Effects on Adjustment to Stressful Life Events. Psychological Bulletin, 136, 257-301. https://doi.org/10.1037/a0018301

[6] Janoff-Bulman, R. (2006) Schema-Change Perspectives on Posttraumatic Growth. In: Calhoun, G. and Tedeschi, R.G., Eds., Handbook of Posttraumatic Growth, Lawrence Erlbaum Associates, London, 81-99.

[7] Kimura, S. and Oishi, K. (2016) An Analysis of Japanese College Athletes' Views Regarding Extracurricular Sports Activities Using a Quantitative Text Analysis. Studies in Institute of Community and Human Services, Rikkyo University, 4, 17-33.

[8] Toyoda, N. and Nakagome, S. (1996) Experiments of Retirements of Athletes-Reconstruction of Identities. Studies for Physical Education, 41, 192-206.

[9] Oba, Y. and Tokunaga, M. (1998) Studies of Retirements of Athletes from Sports-Possible Prevention from Retirements. Thesis for the 25th Academic Conference of Japanese Society of Sports Psychology, 96-97.

[10] Naoi, A. (2009) Psychology on Sports. Bulletin of Center for Clinical Psychology Kinki University, 2, 35-40.

[11] Uemukai, K. (2000) A World of Psychology for Sports. Fukumura Shuppan Inc., Tokyo, 226-237.

[12] Toyoda, N. (2007) The Story of Student Athletes with Injuries. Studies in Biwako Seikei Sport College, 4, 123-125. 